\title{
Discrepancies between MICS-Asia III simulation and observation for surface ozone in the marine atmosphere over the northwestern Pacific Asian Rim region
}

\author{
Hajime Akimoto $^{1}$, Tatsuya Nagashima ${ }^{1}$, Natsumi Kawano ${ }^{1}$, Li Jie ${ }^{2,3,4}$, Joshua S. Fu ${ }^{5,6}$, and Zifa Wang ${ }^{2,3,4}$ \\ ${ }^{1}$ National Institute for Environmental Studies, Onogawa, Tsukuba 305-8506, Japan \\ ${ }^{2}$ The State Key Laboratory of Atmospheric Boundary Layer Physics and Atmospheric Chemistry, Institute of Atmospheric \\ Physics, Chinese Academy of Sciences, Beijing 100029, China \\ ${ }^{3}$ Center for Excellence in Urban Atmospheric Environment, Institute of Urban Environment, Chinese Academy of Sciences, \\ Xiamen, 361021, China \\ ${ }^{4}$ College of Earth Sciences, University of Chinese Academy of Sciences, Beijing, 100049, China \\ ${ }^{5}$ Department of Civil and Environmental Engineering, University of Tennessee, Knoxville, TN 37996, USA \\ ${ }^{6}$ Computational Earth Sciences Group, Computational Sciences and Engineering Division, Oak Ridge National Laboratory, \\ Oak Ridge, TN 37831, USA
}

Correspondence: Hajime Akimoto (akimoto.hajime@ nies.go.jp)

Received: 9 March 2020 - Discussion started: 6 April 2020

Revised: 7 September 2020 - Accepted: 21 October 2020 - Published: 4 December 2020

\begin{abstract}
In order to identify the causes of overestimate of the surface-level $\mathrm{O}_{3}$ mixing ratio simulated by three regional chemical-transport models, NAQPMS v.3 (abbreviated as NAQM in this paper), CMAQ v.5.0.2, and CMAQ v.4.7.1, compared to the EANET observational data at a marine remote site at Oki in July 2010, analyses of hourly $\mathrm{O}_{3}$ mixing ratios and net ozone production were made in the context of MICS-Asia III. In addition to Oki, model-simulated and observational data for two other EANET marine sites, Hedo and Ogasawara, were also examined. Three factors, i.e., longrange transport from the continent, in situ photochemical formation, and dry deposition of $\mathrm{O}_{3}$ on seawater, have been identified as contributing to the overestimate by these regional models at Oki. The calculated $\mathrm{O}_{3}$ mixing ratios during long-range transport from the continent were much higher for all three models than those of the observation. In situ photochemical formation, demonstrated by a distinct diurnal variation which was not discerned in the observational data, was seen in the simulated data of all three models and ascribed to the virtual transport of $\mathrm{NO}_{x}$ from the southern urban areas of the main island of Japan. The overestimate of the $\mathrm{O}_{3}$ mixing ratio in the background oceanic air mass has been discussed referring to dry deposition velocity $\left(V_{\mathrm{d}}\right)$ of $\mathrm{O}_{3}$ over
\end{abstract}

oceanic water. Sensitivity analysis of the dry deposition velocity to the concentration of $\mathrm{O}_{3}$ was made for Oki in July. An increase in $V_{\mathrm{d}}$ from 0.0005 to $0.001 \mathrm{~cm} \mathrm{~s}^{-1}$ used in the standard runs for CMAQ by a factor of 10 decreases the $\mathrm{O}_{3}$ mixing ratio by more than $20 \mathrm{ppbv}$ on an event basis in certain periods of time and by ca. $4.9 \mathrm{ppbv}$ as a monthly mean in July. The dry deposition velocity of $\mathrm{O}_{3}$ in Bohai Bay and the Yellow Sea has been assumed to be comparable to that of the open ocean in all three models, which could have resulted in the overestimate of $\mathrm{O}_{3}$ mixing ratios in this area and also in the long-range transport of $\mathrm{O}_{3}$ from the continent to Oki. A higher value of dry deposition velocity in this marine area is expected considering the higher content of organics in the surface sea layer brought by rivers and atmospheric wet deposition. Empirical measurements of the mixing ratios and dry deposition flux of $\mathrm{O}_{3}$ in this area are highly recommended, since they would affect the simulated mixing ratios in the downwind region in the Pacific Rim region. 


\section{Introduction}

Surface ozone simulation by regional chemical transport models (CTMs) has become widely used and is thought to be well developed considering its long history since the 1980s (e.g., De Wispelaer, 1981) and a well-established underlying fundamental science of tropospheric gas-phase photochemistry (e.g., Akimoto, 2016). Nevertheless, a recent model intercomparison study, MICS-Asia III, has revealed large variability in the simulated spatial distribution of surface ozone $\left(\mathrm{O}_{3}\right)$ mixing ratios in the East Asian region among models and between models and observations ( $\mathrm{Li}$ et al., 2019). Since regional CTMs are commonly used for proposing mitigation policies on how to reduce the emissions of $\mathrm{NO}_{x}$ and NMVOC for controlling photochemical ozone pollution, there is an urgent need to provide useful information on advancing the current understandings of discrepancies among the models and between modeled and observed mixing ratios of $\mathrm{O}_{3}$.

We realize that model intercomparison studies of ozone simulation for air quality are at the stage of identifying the causes of discrepancies and depicting the problems that are used to improve models rather than simply demonstrating the statistical performance of the models and showing the degree of agreement between the simulated ensemble mean and observations. Our previous paper in this special issue (Akimoto et al., 2019) noted a disagreement between the observed mixing ratios of surface $\mathrm{O}_{3}$ in the megacities of Beijing and Tokyo and at a remote oceanic site at Oki and those simulated by three selected regional models, namely WRF-CMAQ, v.5.02 and v.4.7.1, and WRF-NAQPMS v.3. As for the urban areas of megacities, we found that the degree of agreement of the simulated levels of $\mathrm{O}_{3}$ and $\mathrm{NO}$ with the observations were strongly coupled, and we discussed the importance of making comparisons of simulated mixing ratios of precursors $\left(\mathrm{NO}_{x}\right.$ and NMVOC) together with $\mathrm{O}_{3}$ itself. Specifically, we proposed to confirm the potential importance of the heterogeneous "renoxification" reaction of $\mathrm{HNO}_{3}$ to regenerate $\mathrm{NO}_{x}$ on the aerosol surface by comprehensive field observations of $\mathrm{NO}_{y}$. We also identified that the difference in the vertical transport scheme affected the simulated results of $\mathrm{O}_{3}$ significantly.

As for the marine remote site of Oki, an island in the western part of the Sea of Japan, an overestimate of $\mathrm{O}_{3}$ by ca. 20 ppbv compared to observations in July 2010 has been noted for all three selected models. However, the causes of the disagreement between the models and observations were not discussed in the previous paper (Akimoto et al., 2019). Oki is one of the baseline sites for $\mathrm{O}_{3}$ observations, and the $\mathrm{O}_{3}$ level there reflects the amount of transboundary longrange transport of $\mathrm{O}_{3}$ from the Asian continent to the $\mathrm{Pa}$ cific Rim region. It is also a reference "background" site for air quality in Japan. Therefore, a better matching between observational data and model simulation is desired, and elu- cidation of the causes of the overestimates by the models is worth pursuing.

So far, validations of surface $\mathrm{O}_{3}$ in the oceanic area by regional CTMs have rarely been performed. This is because regional CTMs have been applied mainly to the air quality in urban polluted areas with the aim of controlling precursor emissions. However, in the East Asian Pacific Rim region, the continental outflow over the ocean is transported to the downwind land area; thus, a discussion of transboundary pollution is necessarily needed to validate over the oceanic area. In the marine region the dry deposition of $\mathrm{O}_{3}$ on the oceanic water is one of the important parameters which would affect the mixing ratios of $\mathrm{O}_{3}$ in the marine boundary layer. An intensive evaluation of ozone deposition simulations using regional models in East Asia has been reported by Park et al. (2014), but the detailed analysis has been made mostly on land areas, and the discussion in marine regions is limited.

On the other hand, since the oceans cover two-thirds of the earth's surface, the air-sea exchange plays an important role in the tropospheric ozone budget, and substantial discussions on the impact of dry deposition of $\mathrm{O}_{3}$ over oceanic water have been conducted by global CTMs (e.g., Ganzeveld et al., 2009; Young et al., 2013; Hardacre et al., 2015; Luhar et al., 2018). According to the recent estimate, the dry deposition of $\mathrm{O}_{3}$ is found to be $98 \pm 30 \mathrm{Tg} \mathrm{yr}^{-1}$ for the ocean, about $13 \%$ of the global deposition of $723 \pm 87 \mathrm{yr}^{-1}$ (Luhar et al., 2018), in contrast to the previous estimate of the total global dry deposition of $1094 \pm 264 \mathrm{Tg} \mathrm{yr}^{-1}$ (Young et al., 2013), of which about $35 \%$ is to the ocean (Ganzeveld et al., 2009; Hardacre et al., 2015). Hardacre et al. (2015) observed that ozone dry deposition to the water surface has the largest uncertainty compared to other surface types in models.

In the model intercomparison study of MICS-Asia III, substantial overestimate of the mixing ratio of $\mathrm{O}_{3}$ at Oki was revealed only in summer to early autumn (June to September), in contrast to the reasonably good agreement in other seasons (see Fig. S1 in the Supplement). In order to elucidate the discrepancy, an analysis of the simulated results has been made in this study for July, the month with the highest overestimate. The same three models, CMAQ v.5.0.2 and v.4.7.1 and NAQM v.3, as in our previous study (Akimoto et al., 2019) have been used due to the availability of hourly data and process analysis data. In addition to Oki, comparisons at two other oceanic sites over the northwestern Pacific Asian Rim region, Hedo and Ogasawara, which are even more remote than Oki, have been performed. Among the selected three observational sites, Ogasawara was categorized as a "true oceanic site" in the northwestern Pacific (Schultz et al., 2017), Oki is a marine site affected more often by the continental outflow even in the summer, and Hedo is characterized as being between the two sites. 


\section{Models and observational sites}

The selected three models are the same as those in our previous paper, i.e., WRF-CMAQ v.5.0.2, v.4.7.1, and WRFNAQPMS v.3 (abbreviated as NAQM hereafter in this paper). Model calculations by CMAQ v.5.0.2, v.4.7.1, and NAQM were conducted at the University of Tennessee (USA), National Institute for Environmental Studies (Japan), and Institute of Atmospheric Physics (China), respectively. Basic features and the simulated domain of these regional models have been given in previous papers in this special issue (Akimoto et al., 2019; Li et al., 2019). Briefly, the employed horizontal resolution was $45 \mathrm{~km}$ for all the models. The models employed the common meteorological fields from WRF simulations and common emissions of MIX $\left(0.25^{\circ} \times 0.25^{\circ}\right)$ for 2010 (Li et al., 2017), both developed in the MICS-Asia III project. A detailed description of the WRF simulation can be found in Li et al. (2019) and Kong et al. (2020). It was nudged toward the final analysis dataset from the National Centers for Environmental Prediction and National Center for Atmospheric Research (NCEP/NCAR). Dry deposition schemes by Wesely (1989) and M3DRY (Pleim et al., 2001) were used in NAQM and CMAQ, respectively. The initial and boundary conditions were supplied by global models, CHASER for CMAQ v.4.7.1 and NAQM and GEOS-Chem for CMAQ v.5.0.2. The two global models used Wesely (1989) as a dry deposition scheme.

Figure 1 shows three observational sites of EANET (Acid Deposition Monitoring Network in East Asia) at Oki $\left(36.3^{\circ} \mathrm{N}, 133.2^{\circ} \mathrm{E}\right.$; $90 \mathrm{~m}$ a.s.l. $)$, Hedo $\left(26.9^{\circ} \mathrm{N}, 128.2^{\circ} \mathrm{E}\right.$; $60 \mathrm{~m}$ a.s.l.), and Ogasawara $\left(27.1^{\circ} \mathrm{N}, 142.2^{\circ} \mathrm{E} ; 212 \mathrm{~m}\right.$ a.s.l.) (EANET, 2020) which were selected for the comparison of observational data with model simulation. The Oki station is on the northern cliff of Dogo of the Oki islands, the Hedo station is at Cape Hedo located at the northern tip of Okinawa's main island, and the Ogasawara station is on the hill of Chichi of the Ogasawara islands. Measurements of $\mathrm{O}_{3}$ were made by using UV absorption instruments (Horiba APOA-360, -370). The observational data used for the three sites were the $1 \mathrm{~h}$ averaged values in July 2010, provided by the EANET Network Center, Asia Center for Air Pollution Research (ACAP, 2020). Figure 1 also shows the monthly averaged wind field in July.

\section{Results and discussion}

\subsection{Comparison of $\mathrm{O}_{3}$ at $\mathrm{Oki}$, Hedo, and Ogasawara}

Figure 2a-c depict the comparison of the monthly mean diurnal variation of surface $\mathrm{O}_{3}$ mixing ratios in July 2010 between the model simulations and observations at Oki, Hedo, and Ogasawara, respectively. The data shown in Fig. 2a at Oki are the same as those presented in our previous paper (Akimoto et al., 2019) and indicate that the $\mathrm{O}_{3}$ mixing ra-

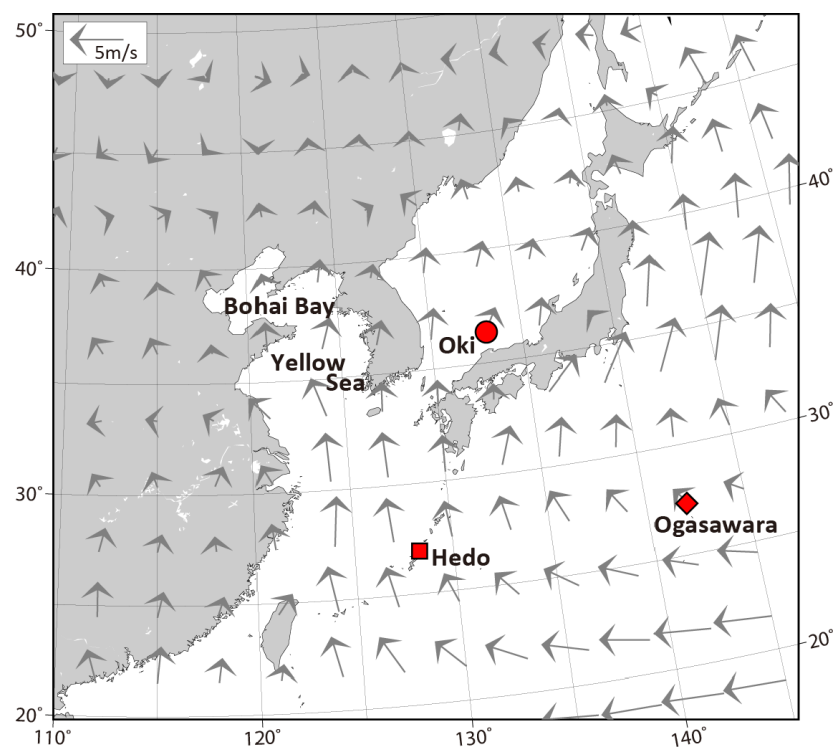

Figure 1. Locations of EANET observation sites at Oki (circle), Hedo (rectangle) and Ogasawara (diamond). Vectors show monthly mean surface wind velocity in July.

tios simulated by all three models fall within the range of $\sim 10 \mathrm{ppbv}$ at the 52-71 ppbv level, as compared to the observational value of 34-43 ppbv. Thus, all three models overestimated the $\mathrm{O}_{3}$ mixing ratio by nearly $20-30$ ppbv. A monthly averaged diurnal amplitude of 17 and $15 \mathrm{ppbv}$ with a daytime maximum and a nighttime minimum can be noted for CMAQ 5.0.2 and NAQM, which is substantially larger than the variability of 7 and $9 \mathrm{ppbv}$ for the simulation by CMAQ 4.7.1 and the observation, respectively.

In contrast to Oki, the monthly averaged observational mixing ratios of $\mathrm{O}_{3}$ at Hedo and Ogasawara are approximately in the same ranges, $12-16$ and $10-14$ ppbv, respectively, with a slight diurnal variation of ca. 4 ppbv. The monthly averaged mixing ratios of $\mathrm{O}_{3}$ at $10-15$ ppbv in July are typical in the marine boundary layer at these remote islands (Pochanart et al., 2002), which are basically under the influence of the Pacific oceanic air mass as shown by the wind field in Fig. 1. The model simulation of NAQM reproduced well the monthly averaged $\mathrm{O}_{3}$ levels at these sites with a slight diurnal variation (ca. 4 and 1 ppbv at Hedo and Ogasawara, respectively). Meanwhile, CMAQ 5.0.2 and 4.7.1 agree well with each other but overestimate the observed monthly averaged $\mathrm{O}_{3}$ mixing ratios by nearly $23-27 \mathrm{ppbv}$ at Hedo and 11-14 ppbv at Ogasawara. These models show a diurnal variation of 9-16 ppbv at Hedo, which is much larger than the observation. The diurnal variation revealed by these models at Ogasawara is less than $1 \mathrm{ppbv}$, agreeing well with NAQM.

In order to clarify the causes of the discrepancies, comparisons of the mixing ratios of $\mathrm{O}_{3}$ on an hourly basis were made at Oki, Hedo, and Ogasawara (Fig. 3a-c). In the ob- 
(a) Oki

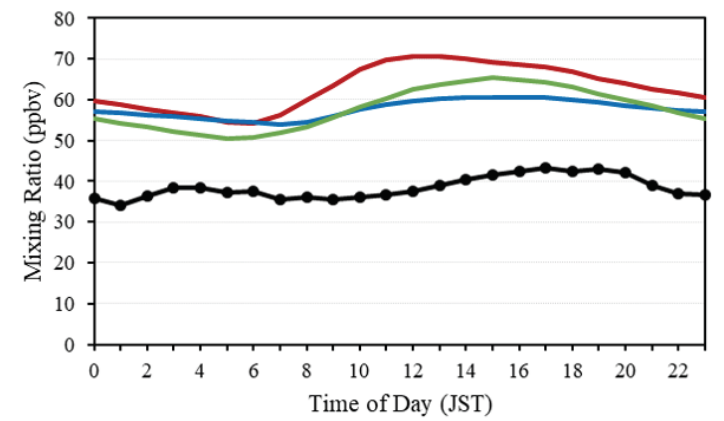

(b) Hedo

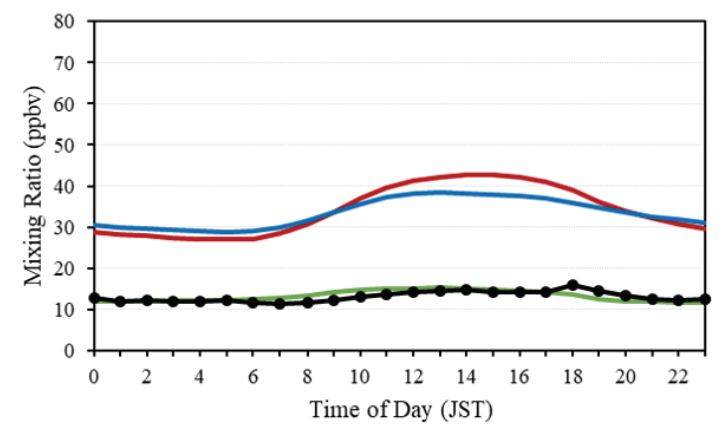

(c) Ogasawara

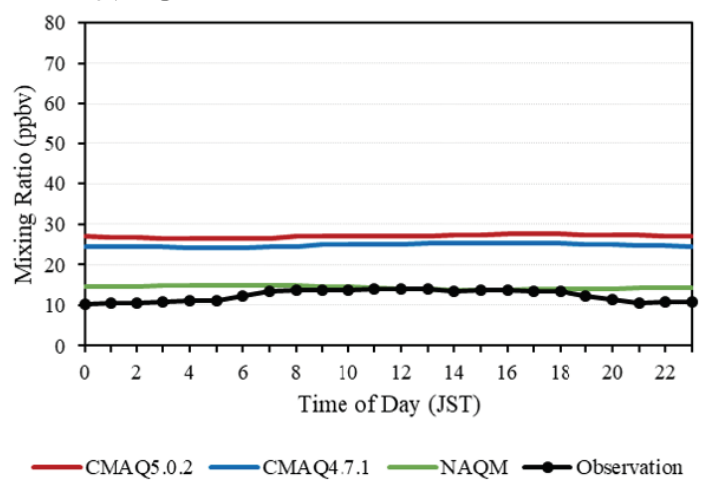

Figure 2. Comparison of monthly averaged diurnal variation of $\mathrm{O}_{3}$ at (a) Oki, (b) Hedo, and (c) Ogasawara in July 2010 between observation and model simulation by CMAQ v.5.0.2 and 4.7.1 and NAQM v.3.

servational data at Oki shown in Fig. 3a, minimum mixing ratios of ca. $20 \mathrm{ppbv}$ are often seen within a short time duration of a few hours, which represents the $\mathrm{O}_{3}$ level in the marine air mass brought by the southerly wind of the summer monsoon from the surrounding oceanic area near Japan, as revealed by Akimoto et al. (1996). The observational data also show that the $\mathrm{O}_{3}$ mixing ratio at Oki often reaches the level of ca. $60 \mathrm{ppbv}$, and the highest $\mathrm{O}_{3}$ level of ca. $80 \mathrm{pbv}$ was observed on 6-8 July. This event is thought to be caused by the long-range transport from the continent (Akimoto et al., 1996). The model simulations captured this event, but the (a) Oki

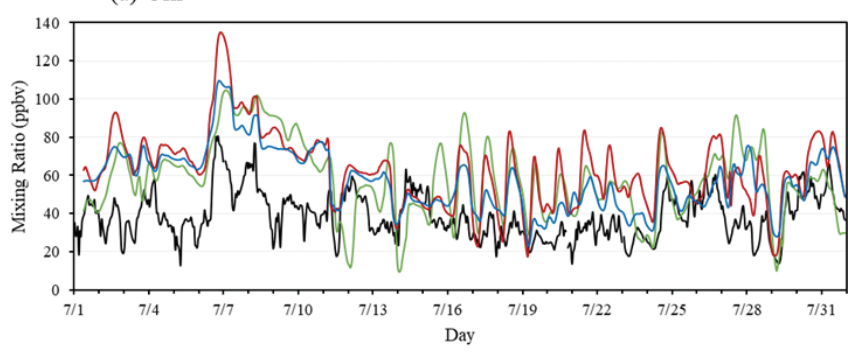

(b) Hedo

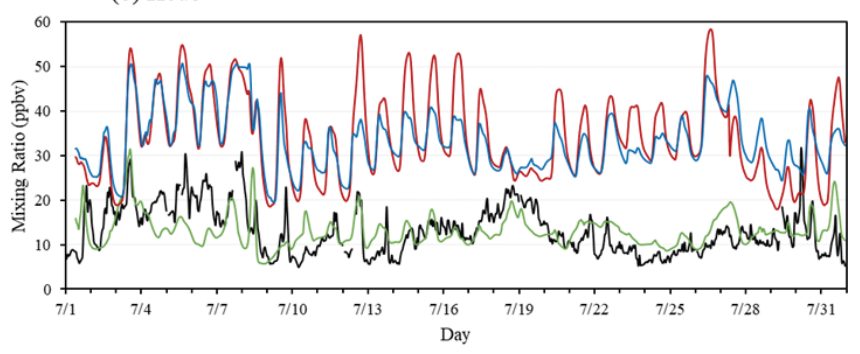

(c) Ogasawara

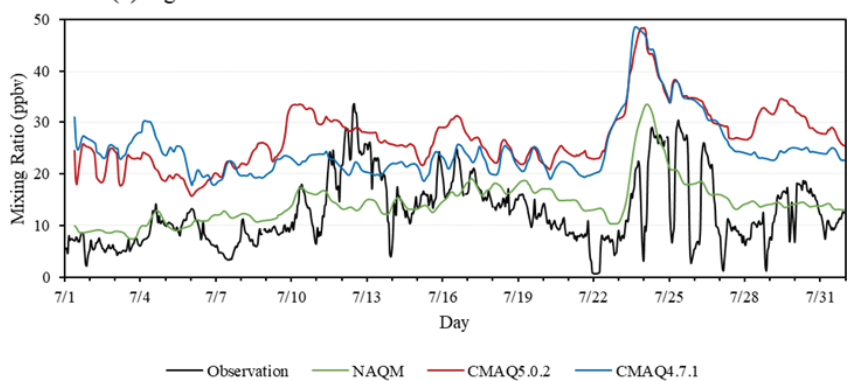

Figure 3. Comparison of diurnal variation of surface $\mathrm{O}_{3}$ mixing ratios at (a) Oki, (b) Hedo, and (c) Ogasawara in July 2010 between observation and model simulation by CMAQ v.5.0.2 and v. 4.7.1 and NAQM v.3. Note that the vertical scale is different for Oki and Hedo/Ogasawara.

estimated peak height of $\mathrm{O}_{3}$ on 6-7 July is much higher, more than 130 ppbv by CMAQ 5.0.2 and ca. 100 ppbv by NAQM and CMAQ 4.7.1.

As seen in Fig. 3a, a distinct diurnal variation with a daytime maximum and a nighttime minimum can be discerned during 16-20 July in the simulations by NAQM and CMAQ 5.0.2. The diurnal variation is less profound in the CMAQ 4.7.1 simulation and is not discernible in the observational data. This feature apparent in the model simulations is thought to be the result of in situ photochemical $\mathrm{O}_{3}$ production during daytime, caused by overestimated $\mathrm{NO}_{x}$ mixing ratios by the models, as will be discussed later in Sect. 3.3.

At Hedo on Okinawa, the observation shows that the minimum (baseline) mixing ratio of $\mathrm{O}_{3}$ in the maritime air mass in this region is $5-10 \mathrm{ppbv}$ in July (Fig. 3b). The figure also shows that the observational $\mathrm{O}_{3}$ level frequently reaches 20-30 ppbv. NAQM reproduced well the background marine $\mathrm{O}_{3}$ levels of ca. $10 \mathrm{ppbv}$ and the higher $\mathrm{O}_{3}$ levels of 20 
30 ppbv. In contrast, a strong diurnal variation is apparent in the CMAQ 5.0.2 simulation with an amplitude of more than $20 \mathrm{ppbv}$ and also in the CMAQ 4.7.1 simulation with a slightly lower amplitude. Furthermore, the maritime background $\mathrm{O}_{3}$ level simulated by these models is ca. 20 ppbv, nearly $10 \mathrm{ppbv}$ higher than the observation. These values of the diurnal variation and background level clearly bring an overestimate of monthly mean $\mathrm{O}_{3}$ levels by more than 20 ppbv (Fig. 2b).

At Ogasawara, a more remote site in the northwestern $\mathrm{Pa}-$ cific about $1000 \mathrm{~km}$ south of Tokyo, the observational $\mathrm{O}_{3}$ mixing ratios in the oceanic air are $2-8$ ppbv (Fig. 3c). However, even at Ogasawara in summer, higher $\mathrm{O}_{3}$ mixing ratios of up to $30 \mathrm{ppbv}$ have been observed. The less than $10 \mathrm{ppbv}$ baseline level of $\mathrm{O}_{3}$ in the remote oceanic air in this region is well reproduced by NAQM, but CMAQ 5.0.2 and 4.7.2 give more than $10 \mathrm{ppbv}$ higher values than the observation. All three models captured well the observed $\mathrm{O}_{3}$ peak on $23-$ 24 July, which can be ascribed to long-range transport from Japan, as will be discussed in Sect. 3.2 below. NAQM reproduced well the observed maximum $\mathrm{O}_{3}$ mixing ratio of ca. 30 ppbv as well as the transport amplitude of $\sim 25$ ppbv. CMAQs gave the similar amount of $\mathrm{O}_{3}$ increase due to the transport, $\sim 25 \mathrm{ppbv}$, but overestimated the peak values due to the overestimate of the baseline mixing ratios. A certain feature of diurnal change peaking at daytime can be seen in both observation and model simulations for several days in Fig. 3c. Although Ogasawara is generally thought to be a real background site based on its remote location over the open Pacific Ocean, the monitoring station is actually surrounded by trees, and the data may be affected by local emissions of biogenic VOCs and soil $\mathrm{NO}_{x}$, which may possibly cause some photochemical activity to form in situ $\mathrm{O}_{3}$ under certain meteorological conditions. Overall, the NAQMsimulated values of monthly mean mixing ratios match the observations, and the CMAQ 5.0.2 and 4.7.1 simulations give ca. 15 ppbv higher $\mathrm{O}_{3}$ values at Ogasawara in July (Fig. 2c).

From these results, we consider that at least three factors, long-range transport, in situ photochemical $\mathrm{O}_{3}$ formation, and background mixing ratio of oceanic $\mathrm{O}_{3}$, would be related to the overestimate of surface $\mathrm{O}_{3}$ at Oki in July by the selected three models.

\subsection{Long-range transport of $\mathrm{O}_{3}$}

At least two high $\mathrm{O}_{3}$ events, one at Oki between 6 and 8 July and the other at Ogasawara on 23 and 24 July, are thought to be caused by long-range transport of $\mathrm{O}_{3}$. In order to confirm the characteristics of these events, the spatial distribution of surface $\mathrm{O}_{3}$ in East Asia obtained by NAQM, CMAQ 5.0.2 and 4.7.1 at 18:00 JST (Japan Standard Time) on 6 July and at 19:00 JST on 23 July are shown in the left and right figures in Fig. $4 \mathrm{a}-\mathrm{c}$, respectively. Figure $4 \mathrm{a}-\mathrm{c}$ (left-hand side) show the event when the plume of continental outflow is transported to the Yellow Sea, South Korea and Japan covering the Oki site. In this event, the simulated surface $\mathrm{O}_{3}$ mixing ratios by NAQM, CMAQ 5.0.2 and 4.7.1 are 104, 135 and $110 \mathrm{ppbv}$, respectively, which are substantially higher than the observational value of $80 \mathrm{ppbv}$. An overestimate of the $\mathrm{O}_{3}$ level in the upwind area of Beijing produced by CMAQ 5.0.2 and 4.7.1 has been identified in our previous paper (Akimoto et al., 2019), which may have contributed to some extent to the overestimate of $\mathrm{O}_{3}$ by these models during this event. The reduction of overestimate over the continent would remove the substantial part of the overestimate of $\mathrm{O}_{3}$ on these days, although the sensitivity analysis has not been made in the present study. On the other hand, NAQM reproduced reasonably well the $\mathrm{O}_{3}$ levels in the urban areas of Beijing in July (Akimoto et al., 2019). Nevertheless, the simulated level of $\mathrm{O}_{3}$ by NAQM during the event is ca. 20 ppbv higher than that of the observation, which implies that an additional factor contributes to the overestimate of $\mathrm{O}_{3}$ in the long-rangetransported air mass.

This additional factor of the overestimate of surface $\mathrm{O}_{3}$ in the long-range-transported $\mathrm{O}_{3}$ from the continent commonly affecting the results of all three selected models could be the result of the overestimate of surface $\mathrm{O}_{3}$ over the Bohai Sea, the Yellow Sea, and the southern part of the Sea of Japan caused by the underestimate of dry deposition velocity of $\mathrm{O}_{3}$ over the seawater in these areas, which will be discussed later in detail in Sect. 3.4.

The right-hand figures in Fig. 4a-c show the long-range transport of $\mathrm{O}_{3}$ over Japan to the Ogasawara islands on 23 July. Under certain meteorological conditions, a high level of $\mathrm{O}_{3}$ over Japan is transported southward toward the Pacific Ocean. The simulated increment of transported $\mathrm{O}_{3}$ to Ogasawara by all three models reproduces the observed value of $\sim 25$ ppbv reasonably well, and the long-range transport of $\mathrm{O}_{3}$ from Japan in this region is not overestimated in either of the models.

\subsection{In situ photochemical formation of $\mathrm{O}_{3}$}

An apparent diurnal variation of $\mathrm{O}_{3}$ with a daytime maximum and a nighttime minimum has been noted in the simulated results at Oki in Fig. 3a for all three models, particularly during 16-23 July, which is not discerned distinctly in the observational data. Such a diurnal variation in the simulated results strongly suggests that an in situ photochemical buildup of $\mathrm{O}_{3}$ occurs in the model simulations. In order to assess the extent of the photochemical buildup and net chemical production of $\mathrm{O}_{3}$ at the remote marine site of Oki, Fig. 5a and $b$ compare the model-simulated mixing ratio of $\mathrm{NO}_{2}$ and $\mathrm{NO}$ with those of $\mathrm{NO}_{2}{ }^{*}$ and $\mathrm{NO}$ observed using a chemiluminescent analyzer with a molybdenum (Mo) catalyzer. Since the Mo catalyzer reduces not only $\mathrm{NO}_{2}$, but also gaseous $\mathrm{HNO}_{3}$ and particulate $\mathrm{NO}_{3}^{-}$to $\mathrm{NO}$, in an unstoichiometric way, the quantity of $\mathrm{NO}_{2}{ }^{*}$ rather than $\mathrm{NO}_{2}$ is reported in the EANET protocol. Since the contribution of $\mathrm{HNO}_{3}$ to $\mathrm{NO}_{2}{ }^{*}$ is significant at remote sites, it is not possible to assess the exact ratio 
(a) NAQM

2010/07/06 18JST

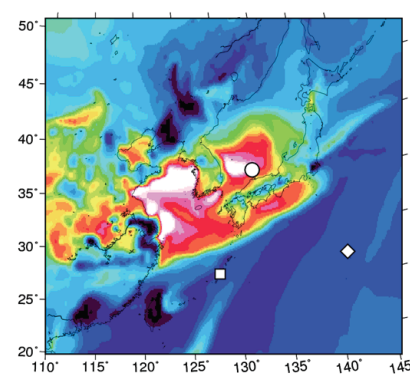

(b) CMAQ 5.0.2 2010/07/06 18JST

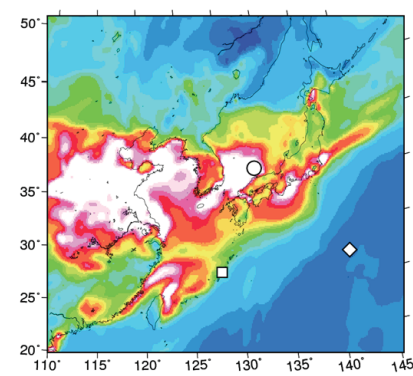

(c) CMAQ 4.7.1 2010/07/06 18JST

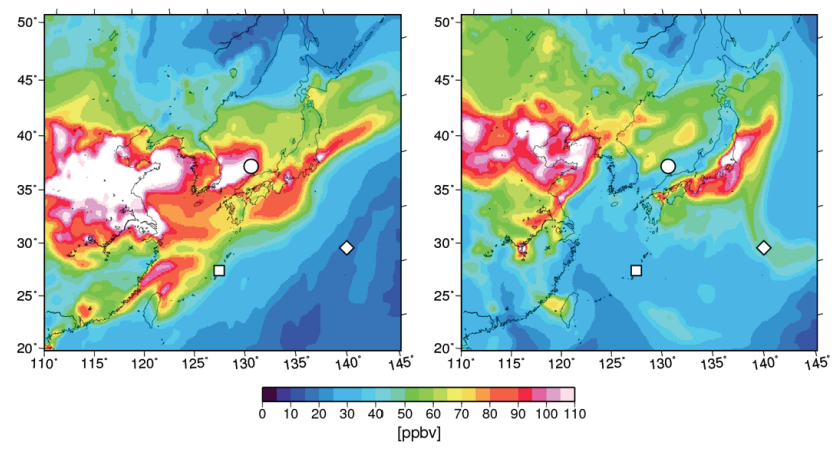

Figure 4. Spatial distribution of surface $\mathrm{O}_{3}$ over northeastern Asia at 18:00 JST on 6 July (left) and 19:00 JST on 23 July (right) 2010 simulated by (a) NAQMS, (b) CMAQ 5.0.2, and (c) CMAQ 4.7.1. Markers denote the locations of observation sites.

of $\mathrm{NO}_{2} / \mathrm{NO}_{2}{ }^{*}$, and thus $\mathrm{NO}_{2}{ }^{*}$ should be used only as a rule of thumb for the upper limit of $\mathrm{NO}_{2}$.

As can be seen in these figures, all the simulated data show significant levels of $\mathrm{NO}_{2}$ of over 2 ppbv in the period from 16 to 21 July, which is substantially higher than the observed $\mathrm{NO}_{2}{ }^{*}$, which is typically lower than 2 ppbv. It should be noted that the temporal variation of $\mathrm{NO}_{2}$ in the simulations by CMAQ 5.0.2 and 4.7.1 is similar, but the absolute mixing ratio simulated by CMAQ 5.0.2 is substantially higher than that simulated by CMAQ 4.7.1. Meanwhile, the temporal pattern of the $\mathrm{NO}_{2}$ mixing ratios simulated by NAQM is quite different from those simulated by CMAQs, and a significantly high level of $\mathrm{NO}_{2}$ of up to $11 \mathrm{ppbv}$ can be seen on 13 July.

It should be pointed out that Oki station is a remote site and that the emission of $\mathrm{NO}_{x}$ within the model grid covering (a) $\mathrm{NO}_{2}$

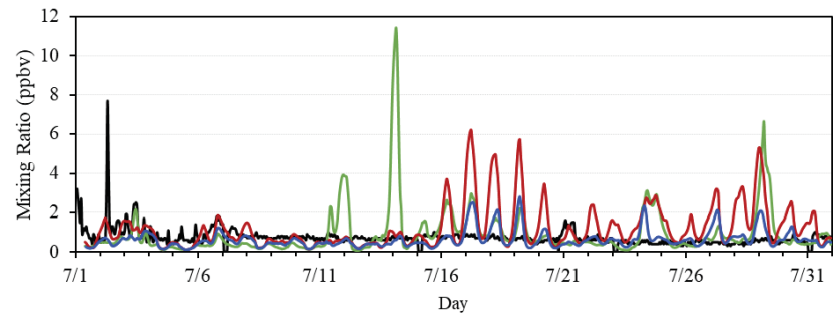

(b) NO

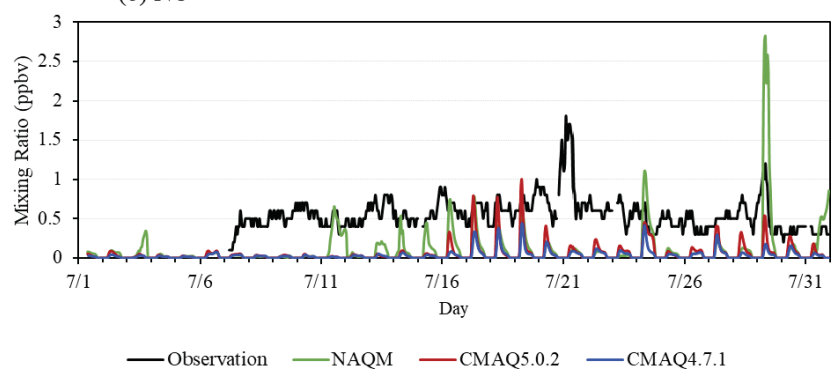

Figure 5. (a) Mixing ratios of $\mathrm{NO}_{2} *$ by observation, $\mathrm{NO}_{2}$ by NAQM, CMAQ v.5.0.2, and CMAQ v. 4.7.1 at Oki in July 2010. (b) Same as (a) but for NO. The sharp peak of $\mathrm{NO}_{2}$ on 2 July would be an artifact or influence of accidental local pollution (see text). The observed concentration of NO in the first week of July is in general under the detection limit and deleted from the figure.

Oki is very low, which gives a low simulated mixing ratio of $\mathrm{NO}_{2}$ of less than $1 \mathrm{ppbv}$ in the early half of the month by all the models. Since all three models use the same emission data supplied by the MICS-Asia III project (Li et al., 2017), the high $\mathrm{NO}_{2}$ over 5 ppbv in Fig. 5a typically seen in the latter half of the month is thought to be transported from urban/industrial sources nearby. A possible source is Matsue and surrounding cities in mainland Japan which are located less than $100 \mathrm{~km}$ south of the Oki site. Model simulations of wrong meteorology may transport much of the $\mathrm{NO}_{x}$ from this area, which does not happen in reality. The different temporal pattern of $\mathrm{NO}_{x}$ between the NAQM and CMAQ simulations is thought to result from the difference in the coupling of transport and chemistry in these models. A high $\mathrm{NO}_{2}$ / NO ratio seen in the model simulation is consistent with the presumption that the virtual source area of $\mathrm{NO}_{x}$ is not close to the site on the island. Similar figures to Fig. 5a-b for Hedo and Okinawa are given in Figs. S5-1 and S5-2 (in the Supplement), respectively. Although Hedo is a remote island site, the area surrounding the station consists of sugar cane field soils emitting substantial NO (Matsumoto et al., 2001), which would give a $\leq \sim 0.5 \mathrm{pptv}$ level of NO in observational data for certain days. The MIX emission inventory used for the modeling considers agricultural sources of $\mathrm{NO}_{x}$ unspecific to crop species. Diurnal variation of $\mathrm{NO}_{2}$ with a smaller amplitude $(\leq \sim 4 \mathrm{ppbv})$ than Oki is seen at Hedo for CMAQ 5.0.2 and 4.7.1 but not for NAQM. At Oga- 
sawara none of the models shows $\mathrm{NO}_{2}$ peaks of more than $0.5 \mathrm{ppbv}$.

In addition to photochemical processes, physical processes of $\mathrm{O}_{3}$ composed of vertical transport from the layer above the marine boundary layer (MBL) coupled with horizontal transport could produce diurnal variation of $\mathrm{O}_{3}$ observed at Oki and Hedo. Figure $6 \mathrm{a}-\mathrm{c}$ depict the hourly net chemical production (chemical production + chemical loss) and physical transport (vertical transport + horizontal transport) of $\mathrm{O}_{3}$ at Oki calculated by NAQM, CMAQ 5.0.2, and CMAQ 4.7.1. Similar figures for Hedo are shown in Fig. S6-1. At Oki substantial photochemical $\mathrm{O}_{3}$ production was simulated by the models up to $10-15 \mathrm{ppbvh}^{-1}$ during the period of $16-$ 23 July. On the other hand, physical transport processes contributed negatively $\left(5-15 \mathrm{ppb} \mathrm{h}^{-1}\right)$ during the period. In order to confirm the possibility of the contribution of upper-layer $\mathrm{O}_{3}$, the vertical profile of $\mathrm{O}_{3}$ simulated by CMAQ 4.7.1 during the month of July is shown in Fig. S6-2. As revealed in Fig. S6-2, $\mathrm{O}_{3}$ in the lower troposphere is typically as low as 20-40 ppbv during the period of 16-23 July, when Oki is apparently covered by Pacific high pressure containing the clean marine air. In contrast, the long-range transport brought high $\mathrm{O}_{3}(80-100 \mathrm{ppb})$ in the lower free troposphere and nearsurface layer on 7-10 July (cf. Fig. 3a).

Thus, virtually simulated relatively high $\mathrm{NO}_{x}$ is thought to bring the in situ photochemical ozone production in the CTMs, which contributes to the overestimate of the monthly averaged mixing ratio of $\mathrm{O}_{3}$ at Oki by all three models. An analysis reveals that the situation is similar at Hedo. Photochemical $\mathrm{O}_{3}$ production of up to $8-10 \mathrm{ppbv} \mathrm{h}^{-1}$ has been simulated by CMAQ 5.0.2 and 4.7.1, as shown in Fig. S6-1. Although Hedo is a remote island site, the local emission of NO from sugar cane field soils emits substantial NO as noted before, which results in some daytime $\mathrm{O}_{3}$ peaks in the observational data as shown in Fig. 3b. The substantial overestimate of the photochemical $\mathrm{O}_{3}$ formation at Hedo produced by CMAQ 5.0.2 and 4.7.1 as revealed by the distinct diurnal variation of $\mathrm{O}_{3}$ in Fig. $3 \mathrm{~b}$ may also be due to the virtual transport of $\mathrm{NO}_{x}$ from urban areas in the southerly part of Okinawa, as in the case of Oki. The overestimate of the in situ photochemical buildup of $\mathrm{O}_{3}$ seems to have resulted from an overestimate of more than ca. $10 \mathrm{ppbv}$ in the monthly mean mixing ratios by these models in addition to the overestimate of the background levels.

At Ogasawara, no such photochemical buildup of $\mathrm{O}_{3}$ of more than $1 \mathrm{ppbh}^{-1}$ can be seen by any of the models. The overestimate of ca. 10 ppbv monthly mean $\mathrm{O}_{3}$ by the CMAQ models (Fig. 2c) is apparently due to the overestimate of background $\mathrm{O}_{3}$ in a clean marine air mass.

\subsection{Dry deposition of $\mathrm{O}_{3}$ on seawater}

Figure $7 \mathrm{a}-\mathrm{c}$ compare the spatial distribution of monthly mean surface ozone mixing ratios in July 2010 in the coastal and oceanic areas of East Asia calculated by NAQM, CMAQ

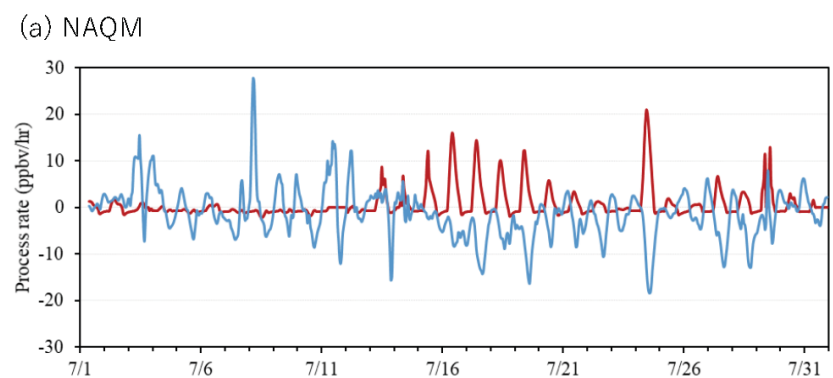

(b) CMAQ v.5.0.2

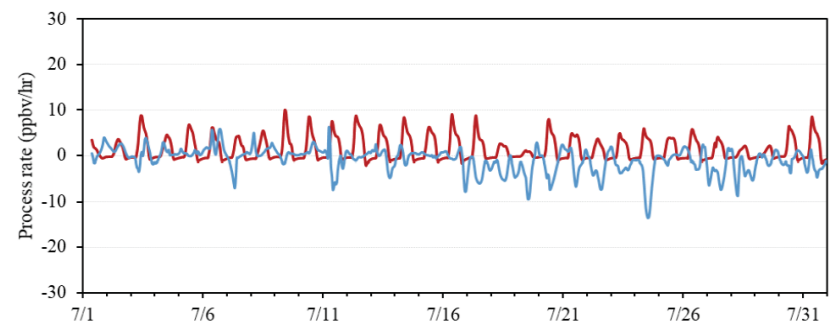

(c) CMAQ V.4.7.1

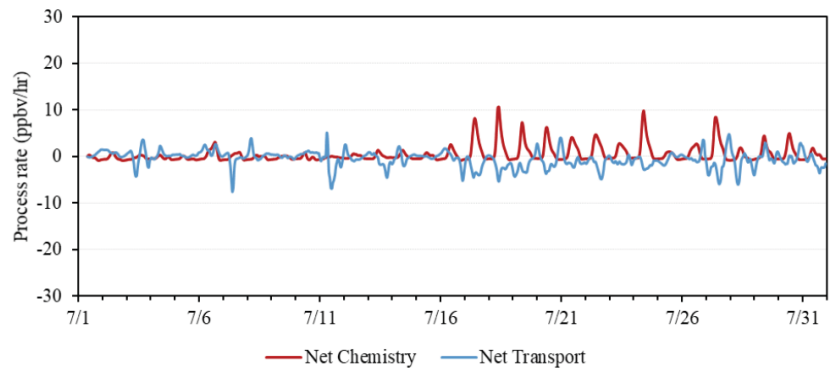

Figure 6. Model-calculated net chemical production and net transport of $\mathrm{O}_{3}$ at Oki in July 2010 by (a) NAQM, (b) CMAQ5.0.1, and (c) CMAQ 4.7.1.

5.0.2, and 4.7.1, respectively. A large variability in the $\mathrm{O}_{3}$ mixing ratio among the models can be seen in heavily polluted land areas, and possible causes of the difference in the megacities of Beijing and Tokyo have been discussed in our previous paper (Akimoto et al., 2019). In addition to the land area, a difference of surface $\mathrm{O}_{3}$ mixing ratios in the oceanic area among the three models can be seen in the figures. The surface $\mathrm{O}_{3}$ simulated by NAQM in the open oceanic area south of Japan is 10-15 ppbv, which is substantially lower than the 25-30 ppbv produced by CMAQ 5.0.2 and 4.7.1. These values correspond well to the calculated monthly mean $\mathrm{O}_{3}$ mixing ratios at the "true oceanic site" Ogasawara, shown in Fig. 2c. Figure 7 also shows that Cape Hedo in Okinawa is at the edge of the Pacific marine air mass, where the coastal air mass could be affected by the continental outflow. The $\mathrm{O}_{3}$ mixing ratio near this site simulated by CMAQ 5.0.2 and 4.7.1 is $30-40 \mathrm{ppbv}$ as compared to ca. $10-20 \mathrm{ppbv}$ calculated by NAQM, which agrees well with the observational value at Hedo (Fig. 2b). Thus, the overestimates of surface ozone at the oceanic sites of Hedo and Ogasawara produced 
by the CMAQ models shown in Fig. 7 are ascribed to an overestimate of $\mathrm{O}_{3}$ in the vast area of the open Pacific Ocean.

We speculate that the cause of this overestimate is possibly an underestimate of dry deposition velocity of $\mathrm{O}_{3}$ on seawater made by these models. Ganzeveld et al. (2009) reported that large uncertainties exist in the magnitude of the air-sea exchange of ozone, with the deposition velocity $\left(V_{\mathrm{d}}\right)$ ranging from 0.01 to $0.15 \mathrm{~cm} \mathrm{~s}^{-1}$ for oceanic water and from 0.01 to $0.1 \mathrm{~cm} \mathrm{~s}^{-1}$ for freshwater. Typically applied values for $V_{\mathrm{d}}$ over the ocean in global models are in the range of $\sim 0.013$ to $0.05 \mathrm{~cm} \mathrm{~s}^{-1}$ (Ganzeveld and Lelieveld, 1995). Oh et al. (2008) studied the effect of dry deposition on the concentration of $\mathrm{O}_{3}$ over the ocean in the northwestern Gulf of Mexico using a regional model. They reported monthly averaged $V_{\mathrm{d}}$ of 0.0026 and $0.0056 \mathrm{~cm} \mathrm{~s}^{-1}$ based on the original and modified Model3/CMAQ models, respectively, and a modified module including iodide reaction showed a significant increase in $V_{\mathrm{d}}$ to $0.0160 \mathrm{~cm} \mathrm{~s}^{-1}$.

Although direct measurements of the ozone deposition flux over the ocean are limited, Helmig et al. (2012) conducted a ship-based eddy covariance ozone flux measurement on five cruises covering the Gulf of Mexico, the South and North Atlantic, the Southern Ocean and the eastern Pacific along Chile. The median $V_{\mathrm{d}}$ for four cruises falls within the range of $0.01-0.02 \mathrm{~cm} \mathrm{~s}^{-1}$ in the off-coast ocean area, while the median $V_{\mathrm{d}}$ measured in the coastal zone fell within the range of $0.24 \pm 0.02 \mathrm{~cm} \mathrm{~s}^{-1}$ (Helmig et al., 2012). A value of $V_{\mathrm{d}}, 0.055 \mathrm{~cm} \mathrm{~s}^{-1}$, over the North Pacific has been reported by the aircraft observation (Lenschow et al., 1982). Thus, dry deposition velocities used in models and obtained in observation over the ocean range between ca. 0.02 and $0.2 \mathrm{~cm} \mathrm{~s}^{-1}$ in about a factor of 100 .

In order to discuss the effect of dry deposition of $\mathrm{O}_{3}$ over the seawater, the spatial distribution of monthly averaged $V_{\mathrm{d}}$ in the continental rim region of the northwestern Pacific Ocean simulated by NAQM and CMAQ 5.0.2 and 4.7.1 is compared in Fig. 8a-c, respectively. The simulated $V_{d}$ of $\mathrm{O}_{3}$ has been calculated by

$V_{\mathrm{d}}=\frac{F_{\mathrm{O}_{3}}}{\left[\mathrm{O}_{3}\right]}$,

where $F_{\mathrm{O}_{3}}$ is the downward deposition flux of $\mathrm{O}_{3}$ (ppbv s cm${ }^{-1}$ ) and $\left[\mathrm{O}_{3}\right]$ is the monthly mean surface $\mathrm{O}_{3}$ mixing ratio (ppbv). Figure 8 shows that the $V_{\mathrm{d}}$ over the northwestern Pacific Ocean south of Japan is typically $0.0015-0.002 \mathrm{~cm} \mathrm{~s}^{-1}$ in the NAQM simulation and $0.0005-$ $0.001 \mathrm{~cm} \mathrm{~s}^{-1}$ in the CMAQ 5.0.2 and 4.7.1 simulations. Thus, even though the values used by NAQM are about twice as large as those used by CMAQs, they are at the lower end of values ever used in the modeling studies mentioned above. Meanwhile, the dry deposition velocity of $\mathrm{O}_{3}$ in the global models used in MICS-Asia III is based on Wesley (1989), and the value of $\sim 0.045 \mathrm{~cm} \mathrm{~s}^{-1}$ has been adopted over the Pacific Ocean, which accords with the values used in some other global models (Ganzeveld and Lelieveld, 1995; Ganzeveld et al., 2009).

The sensitivity of dry deposition velocity on the ocean to the simulated concentration of $\mathrm{O}_{3}$ at the marine sites has been evaluated in the simulation with the varied $V_{\mathrm{d}}$ by factors of $\times 1$ (standard), $\times 2, \times 10$ and $\times 10^{-5}$ (essentially zero) by using CMAQ v5.0.2 with a different model domain setting which includes the area surrounding Japan's main islands and with a horizontal resolution of $15 \mathrm{~km}$. Figure 9 depicts the difference of hourly $\mathrm{O}_{3}$ mixing ratios between the standard runs and those with increased and decreased $V_{\mathrm{d}}$ at Oki in July. As shown in Fig. 9, $\mathrm{O}_{3}$ mixing ratios with the increased $V_{\mathrm{d}}$ by factors of $\times 2$ and $\times 10$ give $\sim 5$ and $\sim 20-30 \mathrm{ppbv}$ lower $\mathrm{O}_{3}$, and with nearly zero $V_{\mathrm{d}}$ they give $\sim 10 \mathrm{ppbv}$ higher $\mathrm{O}_{3}$ as compared to the standard runs at Oki in a certain period of time. Thus, it can be shown that the sensitivity of dry deposition velocity to the $\mathrm{O}_{3}$ concentration is substantial on an event base. However, on a monthly averaged basis, the differences between the standard run and the runs with $V_{\mathrm{d}}$ by factors of $\times 10^{-5}, \times 2$, and $\times 10$ are $1.3,-1.0$, and $-4.9 \mathrm{ppb}$ in July. Since the employment of $V_{\mathrm{d}}=0.01 \mathrm{~cm} \mathrm{~s}^{-1}$, a factor of 10 larger $V_{\mathrm{d}}$ of the present study for CMAQs would be quite plausible considering the range of $V_{\mathrm{d}}$ used in previous studies; at least about half of the $10 \mathrm{ppbv}$ overestimate of background $\mathrm{O}_{3}$ for the Pacific Ocean may be corrected. However, another question would arise from the present sensitivity analysis: why can NAQM reproduce well the background oceanic $\mathrm{O}_{3}$ even though it employed such a low $V_{\mathrm{d}}$ of $0.0015-0.002 \mathrm{~cm} \mathrm{~s}^{-1}$ ? It could be speculated that the $\mathrm{O}_{3}$ mixing ratios in background oceanic air may also be affected by some other factor than the dry deposition velocity, e.g., non-episodic broad spread of continental outflow over this area of the ocean.

It can be noted that the mixing ratios of $\mathrm{O}_{3}$ in Bohai Bay and the Yellow Sea shown in Fig. 7a-c are relatively high for all three models as compared to the surrounding land area. This may be caused by the use of a much smaller deposition velocity of $\mathrm{O}_{3}$ over the ocean closer to the continent. While iodine has been estimated to be most important in increasing the dry deposition velocity of $\mathrm{O}_{3}$ over the ocean, dissolved organic carbon is also thought to contribute significantly to this process (Ganzeveld et al., 2009; Sarwar et al., 2015). Coleman et al. (2010) also showed that in addition to iodide the inclusion of dissolved organic compounds (DOCs) described better the daytime deposition observation in coastal water of the North Atlantic. Thus, the dry deposition velocity of $\mathrm{O}_{3}$ in Bohai Bay and the Yellow Sea is expected to be much higher than that in the open Pacific Ocean. However, as shown in Fig. 8, the dry deposition velocity in this area employed by all three models is even smaller than that in the open Pacific Ocean. This is unreasonable considering the discussion by Ganzeveld et al. (2009), which has been supported by the findings of Helmig et al. (2012). Particularly, the even lower deposition velocity in this area assumed by NAQM compared to that in the open Pacific may have con- 
(a) NAQM

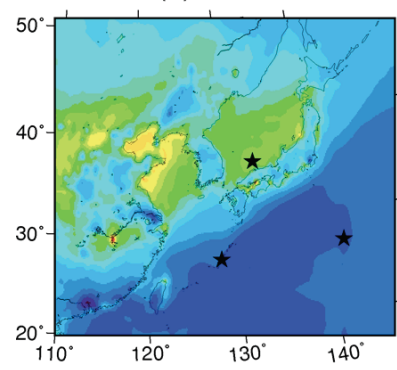

(b) CMAQv5.0.2

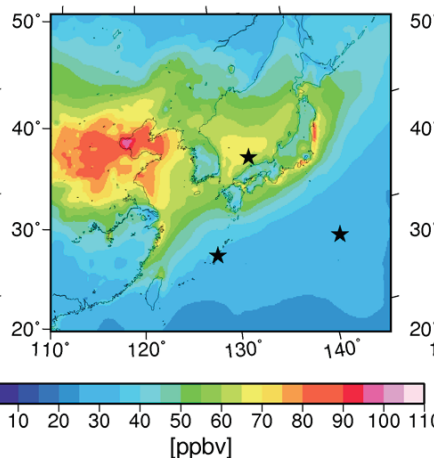

(c) CMAQv4.7.1

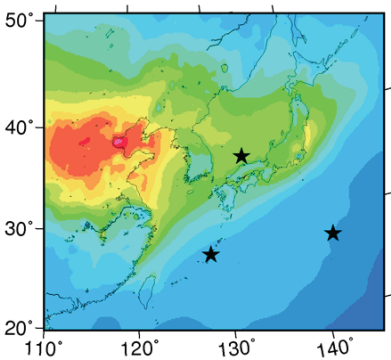

Figure 7. Comparison of the spatial distribution of surface $\mathrm{O}_{3}$ mixing ratios in East Asia in July simulated by (a) NAQM, (b) CMAQ 5.0.2, and (c) 4.7.1.

(a) NAQM

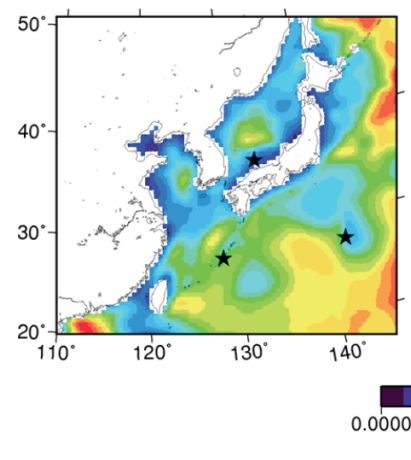

(b) CMAQv5.0.2

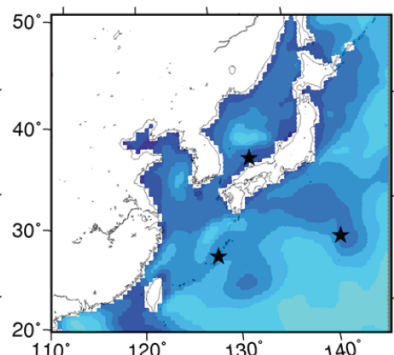

(c) CMAQv4.7.1

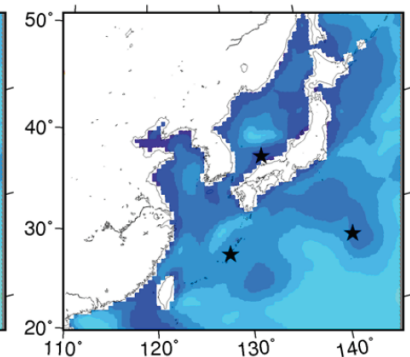

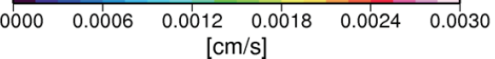

Figure 8. Comparison of the spatial distribution of dry deposition velocity of $\mathrm{O}_{3}$ in East Asia simulated by (a) NAQM, (b) CMAQ 5.0.2, and (c) 4.7.1.

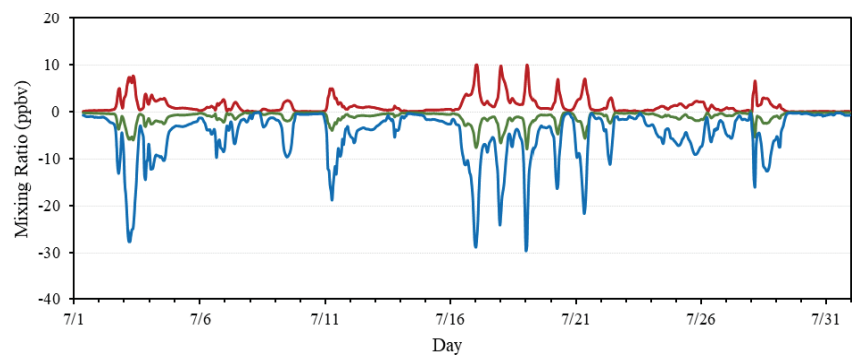

Figure 9. The difference of $\mathrm{O}_{3}$ mixing ratios between the standard $V_{\mathrm{d}}$ run and runs with $V_{\mathrm{d}} \times 10^{-5}$ (red), $\times 2$ (green) and $\times 10$ (blue) at Oki in July 2010 by CMAQ.

tributed substantially to the overestimate of $\mathrm{O}_{3}$ at Oki by this model. The overestimate of the $\mathrm{O}_{3}$ mixing ratio in Bohai Bay and the Yellow Sea would contribute to the overestimate of $\mathrm{O}_{3}$ at $\mathrm{Oki}$ and to the evaluation of transboundary long-range transport of $\mathrm{O}_{3}$ to Korea and Japan. Since the model is highly sensitive to water surface resistance, it is important to empirically obtain the values of dry deposition flux of $\mathrm{O}_{3}$ and its precursors over Bohai Bay and the Yellow Sea.
In addition to the dry deposition on seawater, photochemical gas-phase halogen chemistry mainly by bromine and iodine has been suggested to decrease surface $\mathrm{O}_{3}$ in the marine boundary layer in the Northern Hemisphere (Sarwar et al., 2015). Nagao et al. (1999) reported the 10\%-15\% loss of surface $\mathrm{O}_{3}$ in May-October based on the observation at Ogasawara throughout a year, which they ascribed to the bromine released by heterogeneous reaction of sea salt. Read et al. (2008) reported 8 months of spectroscopic measurements of $\mathrm{BrO}$ and $\mathrm{IO}$ at the Cape Verde Observatory in the tropical eastern North Atlantic and evaluated the annual average daily ozone loss of $3.2 \pm 1.1 \mathrm{ppbv} \mathrm{d}^{-1}$, which amounts to $50 \%$ greater than that simulated by a global chemistry model excluding halogen chemistry. Mahajan et al. (2010) also estimated that the calculated $\mathrm{O}_{3}$ depletion in the marine boundary layer at the Cape Verde islands increases to $\sim 4.5 \mathrm{ppbv} \mathrm{d}^{-1}$ by including the halogen chemistry compared to $\sim 2.5 \mathrm{ppbv} \mathrm{d}^{-1}$ due to $\mathrm{HO}_{x}$ chemistry and deposition to the ocean surface.

Since the present versions of CMAQ and NAQM do not include gas-phase chemistry of halogens, the monthly averaged $\mathrm{O}_{3}$ mixing ratios simulated by these models as shown 
in Fig. 2 would decrease a couple of ppbv according to the above studies (Nagao et al., 1999; Read et al., 2008; Mahajan et al., 2010).

\section{Future research recommendations}

The present and previous (Akimoto et al., 2019) papers aimed to elucidate the causes of discrepancies of surfacelevel ozone at remote marine sites and central megacity sites in East Asia, respectively, among models and between models and observation. Based on the findings in these analyses, a couple of future research recommendations are proposed here in order to solve the issues encountered in model intercomparison studies on surface-level ozone.

1. Measurement of the mixing ratios and dry deposition flux of $\mathrm{O}_{3}$ over Bohai Bay and the Yellow Sea

Surface-level ozone mixing ratios in the marine region of East Asia have been found to be sensitive to the dry deposition velocity of $\mathrm{O}_{3}$ over seawater. Although the dry deposition velocity over Bohai Bay and the Yellow Sea is expected to be much larger than that over the open ocean in the northwestern Pacific due to the enriched organic compounds brought by rivers and atmospheric wet deposition, no such measurements have been conducted to our knowledge. Since the dry deposition velocity of $\mathrm{O}_{3}$ over Bohai Bay and the Yellow Sea may affect the evaluation of transboundary transport of $\mathrm{O}_{3}$ to the downwind region, measurement of the mixing ratios and $V_{\mathrm{d}}$ of $\mathrm{O}_{3}$ in this marine area is highly recommended.

2. Simultaneous comprehensive measurement of $\mathrm{NO}_{y}$ focusing on gaseous $\mathrm{HNO}_{3}$ in urban areas

In order to perform reliable model simulation of surface-level ozone in urban areas for the purpose of proposing an ozone control policy, it is important to verify whether $\mathrm{NO}_{y}$ chemistry is properly incorporated. In particular, model validation for $\mathrm{HNO}_{3}$ is important, since the mixing ratio of gaseous $\mathrm{HNO}_{3}$ is estimated to be comparable to $\mathrm{NO}_{x}$. However, due to technical difficulty, direct measurement of gaseous $\mathrm{HNO}_{3}$ together with other $\mathrm{NO}_{y}$ has rarely been conducted. A field campaign in urban areas for simultaneous measurement of $\mathrm{NO}_{y}$ including direct measurement of gaseous $\mathrm{HNO}_{3}$ (e.g., by chemical ionization mass spectrometry) is highly recommended, focusing on the quantification of the potential importance of the heterogeneous "renoxification" reaction of $\mathrm{HNO}_{3}$ to regenerate $\mathrm{NO}_{x}$ on the aerosol surface.

These activities are recommended to be jointly co-organized by field experimentalists and modelers.

\section{Summary}

Simulations by the regional chemical transport models, NAQM, CMAQ v.5.0.2 and CMAQ v.4.7.1, in the context of MICS Asia III overestimated the observed surface-level ozone at Oki in July 2010 by $20-30$ ppbv. In order to identify the causes of this overestimate, analyses were performed not only for Oki, but for two other EANET marine sites, Hedo and Ogasawara as well. At Hedo and Ogasawara, NAQM reproduced reasonably well the observational values of monthly mean diurnal mixing ratios of $\mathrm{O}_{3}$, while the two CMAQ models overestimated the observation by 23-27 and 11-14 ppbv, respectively.

Three factors have been identified as the possible cause of overestimates made by the model simulations at Oki: (i) long-range transport of $\mathrm{O}_{3}$ from the continent, (ii) in situ photochemical formation of $\mathrm{O}_{3}$, and (iii) dry deposition of $\mathrm{O}_{3}$ on seawater. An overestimate of transported $\mathrm{O}_{3}$ from the continent can be identified at Oki in July for all three models. The overestimate for the CMAQ models may partly be ascribed to an overestimate of the $\mathrm{O}_{3}$ mixing ratio in the source region of China. An overestimate of long-range-transported $\mathrm{O}_{3}$ was also seen in NAQM which reproduced the mixing ratio in Beijing reasonably well. The cause of overestimate of long-range-transported $\mathrm{O}_{3}$ by NAQM may partly be ascribed to the possible overestimate of the marine boundary layer $\mathrm{O}_{3}$ in Bohai Bay and the Yellow Sea due to the too small deposition velocity of $\mathrm{O}_{3}$ over the seawater assumed in the models.

The overestimate of the monthly averaged mixing ratio of $\mathrm{O}_{3}$ at Oki has been ascribed partly to the in situ photochemical formation, which was demonstrated by the distinct diurnal variation of $\mathrm{O}_{3}$ produced by all three models but not discernible in the observational data. Such an in situ formation of $\mathrm{O}_{3}$ was found to be caused by the virtual transport of $\mathrm{NO}_{x}$ in the model simulation from the urban areas of mainland Japan to Oki.

At the Hedo and Ogasawara sites, an overestimate of $\mathrm{O}_{3}$ in the oceanic air mass was found in CMAQ 5.0.2 and 4.7.1, while a reasonably good agreement with observational data was obtained by NAQM. The overestimate by the CMAQ models was discussed in relation to the dry deposition velocity of $\mathrm{O}_{3}$ on seawater. It has been identified that $\mathrm{O}_{3}$ mixing ratios over Bohai Bay and the Yellow Sea are higher than those over the surrounding land surface for all three models, which was ascribed to the employment of too small a dry deposition velocity on seawater in this area in spite of higher contents of organics due to the deposition from the atmosphere and rivers.

Data availability. The EANET observational dataset used in this study is available at http://www.acap.asia (ACAP, 2020). 
Supplement. The supplement related to this article is available online at: https://doi.org/10.5194/acp-20-15003-2020-supplement.

Author contributions. HA analyzed the data and wrote the first draft of the paper. TN, JL, and JSF provided the model simulation data for their own models and conducted discussions for the paper. NK conducted the model simulation of sensitivity analysis of dry deposition. ZW contributed to the availability of modeling data as a coordinator of MICS-Asia III.

Competing interests. The authors declare that they have no conflict of interest.

Special issue statement. This article is part of the special issue "Regional assessment of air pollution and climate change over East and Southeast Asia: results from MICS-Asia Phase III". It is not associated with a conference.

Acknowledgements. We would like to thank Edit Nagy-Tanaka at NIES for English language editing.

Financial support. This research has been supported by the Ministry of the Environment, Japan (Environment Research and Technology Development Fund (grant no. S12-1)) and the Natural Science Foundation of China (grant no. 41620104008).

Review statement. This paper was edited by Qiang Zhang and reviewed by three anonymous referees.

\section{References}

ACAP: Monitoring data, available at: http://www.acap.asia, last access 10 January 2020.

Akimoto, H.: Atmospheric Reaction Chemistry, Springer Japan, Tokyo, 2016.

Akimoto, H., Mukai, H., Nishikawa, M., Murano, K., Hatakeyama, S. Liu, C.-M., Buhr, M. Hsu, K. J., Jaffe, D. A., Zhang, L., Honrath, R., Merrill, J. T., and Newell, R. J.: Long-range transport of ozone in the East Asian Pacific rim region, J. Geophys. Res., 101, 1999-2010, 1996.

Akimoto, H., Nagashima, T., Li, J., Fu, J. S., Ji, D., Tan, J., and Wang, Z.: Comparison of surface ozone simulation among selected regional models in MICS-Asia III - effects of chemistry and vertical transport for the causes of difference, Atmos. Chem. Phys., 19, 603-615, https://doi.org/10.5194/acp-19-6032019, 2019.

Coleman, L., Varghese, S., Jennings, S. G., and O'Dowd, C. D.: Regional-scale ozone deposition to northeast Atlantic waters, Adv. Meteorol., 243701, 16 pp., https://doi.org/10.1155/2010/243701, 2010.
De Wispelaer, C. (Ed.): Air Pollution Modeling and its Application I, Plenum Press, New York, 1981.

EANET: EANET site information, available at: http://www.eanet asia/about/site-information/, last access: 23 January 2020.

Ganzeveld, I., Helmig, D., Fairall, C. W., Hare, J., and Pozzer, A.: Atmosphere-ocean ozone exchange: A global modeling study of biogeochemical, atmospheric, and waterside turbulence dependencies, Global Biogeochem. Cy., 23, GB4021, https://doi.org/10.1029/2008GB003301, 2009.

Ganzeveld, L. and Lelieveld, J.: Dry deposition parameterization in a chemistry general circulation model and its influence on the distribution of reactive trace species, J. Geophys. Res., 100, 20999-21012, https://doi.org/10.1029/95JD02266, 1995.

Hardacre, C., Wild, O., and Emberson, L.: An evaluation of ozone dry deposition in global scale chemistry climate models, Atmos. Chem. Phys., 15, 6419-6436, https://doi.org/10.5194/acp15-6419-2015, 2015.

Helmig, D., Lang, E. K., Bariteau, L., Boylan, P., Fairall, C. W., Ganzeveld, L., Hare, J. E., Hueber, J., and Pallandt, M.: Atmosphere-ocean ozone fluxes during the TexAQS 2006, STRATUS 2006, GOMECC 2007, GasEx 2008, and AMMA 2008 cruises, J. Geophys. Res., 117, D04305, https://doi.org/10.1029/2011JD015955, 2012.

Kong, L., Tang, X., Zhu, J., Wang, Z., Fu, J. S., Wang, X., Itahashi, S., Yamaji, K., Nagashima, T., Lee, H.-J., Kim, C.-H., Lin, C.-Y., Chen, L., Zhang, M., Tao, Z., Li, J., Kajino, M., Liao, H., Wang, Z., Sudo, K., Wang, Y., Pan, Y., Tang, G., Li, M., Wu, Q., Ge, B., and Carmichael, G. R.: Evaluation and uncertainty investigation of the $\mathrm{NO}_{2}, \mathrm{CO}$ and $\mathrm{NH}_{3}$ modeling over China under the framework of MICS-Asia III, Atmos. Chem. Phys., 20, 181-202, https://doi.org/10.5194/acp-20-181-2020, 2020.

Lenschow, D. H., Pearson Jr., R., and Stankov, B. B.: Measurements of Ozone Vertical Flux to Ocean and Forest, J. Geophys. Res., 87, 8833-8837, 1982.

Li, J., Nagashima, T., Kong, L., Ge, B., Yamaji, K., Fu, J. S., Wang, X., Fan, Q., Itahashi, S., Lee, H.-J., Kim, C.-H., Lin, C.Y., Zhang, M., Tao, Z., Kajino, M., Liao, H., Li, M., Woo, J.H., Kurokawa, J., Wang, Z., Wu, Q., Akimoto, H., Carmichael, G. R., and Wang, Z.: Model evaluation and intercomparison of surface-level ozone and relevant species in East Asia in the context of MICS-Asia Phase III - Part 1: Overview, Atmos. Chem. Phys., 19, 12993-13015, https://doi.org/10.5194/acp-19-129932019, 2019.

Li, M., Zhang, Q., Kurokawa, J.-I., Woo, J.-H., He, K., Lu, Z., Ohara, T., Song, Y., Streets, D. G., Carmichael, G. R., Cheng, Y., Hong, C., Huo, H., Jiang, X., Kang, S., Liu, F., Su, H., and Zheng, B.: MIX: a mosaic Asian anthropogenic emission inventory under the international collaboration framework of the MICS-Asia and HTAP, Atmos. Chem. Phys., 17, 935-963, https://doi.org/10.5194/acp-17-935-2017, 2017.

Luhar, A. K., Woodhouse, M. T., and Galbally, I. E.: A revised global ozone dry deposition estimate based on a new two-layer parameterisation for air-sea exchange and the multi-year MACC composition reanalysis, Atmos. Chem. Phys., 18, 4329-4348, https://doi.org/10.5194/acp-18-4329-2018, 2018.

Mahajan, A. S., Plane, J. M. C., Oetjen, H., Mendes, L., Saunders, R. W., Saiz-Lopez, A., Jones, C. E., Carpenter, L. J., and McFiggans, G. B.: Measurement and modelling of tropospheric reactive halogen species over the tropical Atlantic Ocean, At- 
mos. Chem. Phys., 10, 4611-4624, https://doi.org/10.5194/acp10-4611-2010, 2010.

Matsumoto, J., Hirokawa, J., Akimoto, H., and Kajii, Y.: Direct measurement of $\mathrm{NO}_{2}$ in the marine atmosphere by laser-induced fluorescence technique, Atmos. Environ., 35, 2803-2814, 2001.

Nagao, I., Matsumoto, K., and Tanaka, H.: Sunrise ozone destruction found in the sub-tropical marine boundary layer, Geophys. Res. Lett., 26, 3377-3380, 1999.

Oh, I.-B., Byun, D. W., Kim, H.-C., Kim, S., and Cameron, B.: Modeling the effect of iodide distribution on ozone deposition to seawater surface, Atmos. Environ., 42, 4453-4466, 2008.

Park, R. J., Hong, S. K., Kwon, H.-A., Kim, S., Guenther, A., Woo, J.-H., and Loughner, C. P.: An evaluation of ozone dry deposition simulations in East Asia, Atmos. Chem. Phys., 14, 7929-7940, https://doi.org/10.5194/acp-14-7929-2014, 2014.

Pleim, J. E., Xiu, A., Finkelstein, P. L., and Otte, T. L.: A coupled land-surface and dry deposition model and comparison to field measurements of surface heat, moisture, and ozone fluxes, Water Air Soil Pollut., 1, 243-252, 2001.

Pochanart, P., Akimoto, H., Kinjo, Y., and Tanimoto, H.: Surface ozone at four remote island sites and the preliminary assessment of the exceedances of its critical level in Japan, Atmos. Environ., 36, 4235-4250, 2002.

Read, K. A., Mahajan, A. S., Carpenter, L. J., Evans, M. J., Faria, B. V. E., Heard, D. E., Hopkins, J. R., Lee, J. D., Moller, S. J., Lewis, A. C., Mendes, L., McQuaid, J. B., Oetjen, H., Saiz-Lopez, A., Pilling, M. J., and Plane, J. M. C.: Extensive halogen-mediated ozone destruction over the tropical Atlantic Ocean, Nature, 453, 1232-1235, 2008.
Sarwar, G., Gantt, B., Schwede, D., Foley, K., Mathur, R., and SaizLopez, A.: Impact of enhanced ozone deposition and halogen chemistry on tropospheric ozone over the Northern Hemisphere, Environ. Sci. Technol., 49, 9203-9211, 2015.

Schultz, M. G., Schröder, S., Lyapina, O., et al.: Tropospheric Ozone Assessment Report: Database and metrics data of global surface ozone observations, Elem. Sci. Anth., 5, 58, https://doi.org/10.1525/elementa.244, 2017.

Wesely, M. L.: Parameterization of surface resistances to gaseous dry deposition in regional-scale numerical models, Atmos. Environ., 23, 1293-1304, 1989.

Young, P. J., Archibald, A. T., Bowman, K. W., Lamarque, J.-F., Naik, V., Stevenson, D. S., Tilmes, S., Voulgarakis, A., Wild, O., Bergmann, D., Cameron-Smith, P., Cionni, I., Collins, W. J., Dalsøren, S. B., Doherty, R. M., Eyring, V., Faluvegi, G., Horowitz, L. W., Josse, B., Lee, Y. H., MacKenzie, I. A., Nagashima, T., Plummer, D. A., Righi, M., Rumbold, S. T., Skeie, R. B., Shindell, D. T., Strode, S. A., Sudo, K., Szopa, S., and Zeng, G.: Preindustrial to end 21 st century projections of tropospheric ozone from the Atmospheric Chemistry and Climate Model Intercomparison Project (ACCMIP), Atmos. Chem. Phys., 13, 20632090, https://doi.org/10.5194/acp-13-2063-2013, 2013. 